\title{
Perceived barriers for distance teaching in higher education during the COVID-19 crisis: "I never did a video before"
}

\author{
Juan-José Boté-Vericad \\ Departament de Biblioteconomia, Documentació i Comunicació Audiovisual and Centre de Recerca en \\ Informació, Comunicació i Cultura, Universitat de Barcelona, C/ Melcior de Palau 140, 08014 ES, \\ Barcelona, Spain \\ E-mail: juanjo.botev@ub.edu
}

The purpose of this paper is to analyse barriers that a selected group of professors at the University of Barcelona faced due to the COVID-19 restrictions, their perceptions of the current situation, and the potential for long-term adoption of new teaching methods that emerged from this situation.

It remains unclear whether these professors will return to traditional teaching methods as soon as COVID-19 restrictions are lifted, or whether they will adopt digital teaching elements in the future. The group of professors sought technical help during the first weeks of online teaching. This research uses a qualitative approach through a self-administered qualitative survey. We analyse data using open-ended questions about barriers they faced in creating educational content via video. Answers were coded and analysed using thematic analysis with an inductive approach. We identified two overarching themes: educational material delivery and professors and distance teaching.

Findings indicate that professors lacked digital skills as well as a lack of knowledge of emergency remote teaching. There were differences in their perceptions of teaching methodologies. The results are discussed in relation to research from other countries about the use of videos for teaching before and during the COVID-19 crisis.

Keywords: COVID-19, digital literacy, educational video, higher education, Library Information Science, thematic analysis, qualitative research

\section{Introduction}

This paper is a case study of the professors in Spain at the University of Barcelona (hereafter UB) and the challenges they faced in distance teaching during the COVID19 lockdown from 13 March 2020 until 30 April 2020. It addresses technical barriers during emergency remote teaching and related pedagogical reflections.

At the international level, several countries implemented mobility restrictions and/or an entire population lockdown, for different reasons. One was to stop the spread of the COVID-19 (SARS-CoV-2) (Fang et al., 2020), but this measure depends on the ability to estimate infection risk in different areas (Espinoza et al., 2020). As such, not all countries approached restrictions in the same manner. In Sweden, voluntary social distancing was required with primary and secondary schools remaining open, while universities were closed (Anderson, 2020; Dahlberg et al., 2020). 
Initially, in Spain, there were government mobility restrictions during the COVID19 outbreak from 13 March until 30 April 2020. Consequently, the Spanish population faced lockdown at home and a significant number of professionals had to work remotely with the exception of essential services as declared by the Spanish Government (Gobierno de España, 2020).

In the case of the educational system, it was estimated that it could be done remotely, so university professors were forced to work remotely, trying to teach digitally. This created several challenges for professors, not only regarding changes in their method of teaching, but also in adapting to new technology. Among the issues they faced was teaching through video conferencing applications or the new challenge of creating educational videos. In Spain, only four universities could easily adapt because they had already adopted distance learning as the core method of course delivery. These universities were the major public distance university, the Universidad de Educación a Distancia (UNED) and private universities like Universidad a Distancia de Madrid (UDIMA), the Universitat Oberta de Catalunya (UOC), and the Universidad Internacional de la Rioja (UNIR). The remaining Spanish universities offered face-toface teaching as their educational core before the lockdown and, in some cases, they offered blended courses as well.

The situation at the UB was no different from other Spanish universities. At UB, professors can access a virtual campus through the Moodle software platform to upload learning resources for students such as lectures, quizzes, and other educational resources to share course content, and also to assess student knowledge. Nevertheless, Moodle is not designed for the creation of virtual teaching sessions via video, unless certain third-party applications are integrated. UB provides their professors with access to Microsoft cloud software and a set of applications, two of which work with videos. First, Skype for Business enables teaching through live sessions but it has several limitations for distance teaching. Second, Microsoft Stream, which is an asynchronous video platform that allows the uploading of videos. Microsoft Stream is useful for publishing video lectures, tutorials, and other types of educational material, but its use is restricted to the organization; videos are not visible from a search engine.

Finally, UB provided professors with another distance teaching tool, Blackboard Collaborate which can be integrated with Moodle. Blackboard Collaborate permits live sessions and interactions with students, as well as dividing them into groups, allowing for a collaborative whiteboard and other facilities such as lecture recording. Students can view a recorded session of a class they were unable to attend. One of the limitations of Blackboard Collaborate is that professors cannot see all of the students at the same time. Browsers like Google Chrome only make it possible to see five participants at a same time while Firefox only allows for two participants to be seen.

In relation to this, we focus on two main research questions:

- RQ1: Have faculty professors faced barriers during the COVID-19 lockdown in distance teaching?

- RQ2: Have professors made any change made in regard to their teaching methodology? 
This paper is organised as follows: Sections 2 and 3 present a background of the current situation, and a literature review focused on academic barriers in distance teaching. This is followed by Section 4, which describes the methods and materials used in this paper. Section 5, shows results and provides an analysis of themes and subthemes. Finally, Section 6 is a discussion of the results and conclusions.

\section{Background}

\subsection{Mobility restrictions}

Mobility restrictions bring varying economic and social consequences, and affect the poorer segment of the population more severely (Bonaccorsi et al., 2020).

At UB, mobility restrictions especially affected low-income students because most of them combine their studies with part-time or even full-time work to pay expenses and university tuition. These students represent $54 \%$ of low-income students and $40 \%$ of the overall student body as indicated in a report from the Student Observatory of UB (Alegre et al., 2016; Calduch et al., 2017). One of the consequences of the lockdown was that some students, particularly those already economically disadvantaged, did not have an internet connection to attend courses regularly, causing a digital divide. To alleviate the situation, UB created an emergency grant for economically vulnerable students (Universitat de Barcelona, 2020).

\subsection{Higher education transformation}

Moving universities to online teaching has brought about a sudden transformation. Teachers who were used to traditional teaching methods such as lectures, oral interaction, and using the blackboard or slides in class were more likely to face some barriers when forced to deliver their lectures in a completely different way. These professors had to digitally transform their lectures and, in some cases, learn from scratch how to create digital content adapted to remote learning.

This sudden digital transformation forced most professors to create new digital learning materials, while bearing in mind those students without good Internet connections or with access only to a mobile phone. In this case, the mobile learning (hereafter m-learning) approach could be the best option for professors searching for ways to continue giving lectures. Learning materials could include PowerPoint presentations to accompany lectures or assigning additional reading to students. Creating video and audio content for asynchronous teaching, such as podcasts requires new skills. Podcasts have been shown to be one of the easiest and best ways to deliver traditional lectures using voice as they do not usually require fast broadband. In the field of medicine, a successful podcast included a mix of personal notes and clinical content (Wolpaw \& Harvey, 2020) and its narrative style made it enjoyable to listen to (Roth et al., 2020).

There are three possible options for the future: a) campuses open up for face-to-face education; b) campuses plan for online terms; or c) campuses find ways to blend a 
physical presence with online learning, depending on local conditions (Alexander, 2020). In Spain, universities provided different solutions, depending on the students in some subjects, building conditions, and the use of laboratories when necessary (Nuño, 2020).

\subsection{M-learning and the "new normal"}

The academic year 2020-21, was called the "new normal" by some. The "new normal" means that education at universities will be delivered by a hybrid model. Face-to-face courses will probably need to be combined with distance teaching. However, educational materials cannot be delivered in the same format and must be adapted to m-learning.

M-learning is a part of e-learning, with a focus on the use of mobile devices like tablets or smartphones. Since most students have mobile devices, it makes sense to adapt the design of learning materials to these devices. M-learning provides the possibility of studying anywhere with a mobile device. An increasing number of students are using these devices to learn as well as for personal use. There are several benefits for students with m-learning.

First, it permits the use of any educational material such as a slide presentation or a podcast (Mbabazi et al., 2018). Second, it permits the use of additional software to learn and to create content, and it allows for working on assignments when they are adequately designed for mobile devices (Mejía, 2020).

The literature shows different findings when integrating learning materials into mobile applications. For instance, in Lampung Province (Indonesia), a quantitative study surveyed 39 physics teachers via Whatsapp. Participants agreed that the use of mobile phones in physics learning during face-to-face hours could improve the learning process (Suyatna, 2019). However, since learning material must fit onto a mobile device, not all specialities have mobile-adapted software, or not all experiences were successful. In a study in Indonesia in the field of chemistry comparing two groups of 24 first-year students it was found that the students' experiences with m-learning resources were good. However, there were still many issues to be reviewed such as the ability to navigate (Ramud et al., 2018). Another study in the United States, surveying 293 students from different specialities, found issues relating to information literacy and technology. Participants did not use their smartphones for academic information not only because they lacked competency, but also because of a lack of mobile versions of websites. In particular, the screen size was often too small (Mbabazi et al., 2018). It seems highly relevant for most distance learning scenarii that mobile learning materials have to be accessible from small screens, and students need information literacy training.

\subsection{Emergency remote teaching}

Contrary to what may have been thought initially, emergency remote teaching is not online learning (Hodges et al., 2020a). During the COVID-19 outbreak there was 
a confusion between the terms "distance learning" and "emergency remote teaching". In distance learning, learners and learning resources are planned and designed to be delivered virtually (Borzkurt \& Sharma, 2020). Online learning can be an instructional strategy chosen by the learner with a design, learning objectives, a delivery format, a platform, an organizational structure, an interaction type, an assessment, and, finally, an evaluation plan (Gacs et al., 2020).

Emergency remote teaching (hereafter ERT) is shifting instructional education to unplanned distance learning. It is forced and not chosen by learners or professors. Due to the COVID-19 outbreak, remote teaching has become a temporary emergency solution. Moreover, remote teaching is not simply replicating face-to-face teaching to online environments. This can lead to ineffective learning experiences (Schlesselman, 2020). Remote teaching needs to be planned carefully to avoid frustration for students, as well as for professors.

In an emergency situation, humans have the right to education based on the assumption that students are treated equally. However, shifting a face-to-face model to an e-Learning environment in ERT created many obstacles for students and professors in higher education (Affouneh et al., 2020).

Remote teaching encompasses a set of personal skills that not every professor possesses. For instance, in New South Wales (Australia), a group of 99 teachers were asked about the personal attributes for quality teaching in remote rural areas. These non-academic attributes were based on 12 indicators based on three clusters: empathy and communication, organisation and planning and resilience and adaptability. It was found that teacher adaptability and cultural competence were complementary attributes that could be a part of the interview process for new teachers (Durksen \& Klassen, 2018).

In Oman, a study during the COVID-19 outbreak found that shifting from faceto-face teaching to ERT presented students in rural areas with challenges accessing lectures because of poor Internet connections. It was also found that a large number of students tended to access their course materials through Moodle right before assignments were due. In this same study, it was also found that adapting to new teaching and learning environments was challenging, and that the atmosphere at home was not always suited to teaching and learning (Mohmmed et al., 2020).

Another study of 20 Philippine teachers in China found that teachers implementing ERT generally have a positive attitude toward planning their teaching strategy, with a plan B in case plan A did not work. However, it was also found that teachers needed some guidance and an instructional model for remote teaching (Talidong, 2020).

Some ERT guides have been developed to help teachers and professors to understand the context, teaching process and roles, student involvement, learning processes, and desired outcomes (Flynn \& Kerr, 2020; Hodges et al., 2020b; Oranburg, 2020). Other studies in the USA of K-12 pupils have proposed an emergency remote teaching environment (ERTE), a conceptual framework for managing future educational crises in addition to COVID-19 (Whittle et al., 2020), along with strategies for a self-regulated learning (SRL) framework to support remote learning (Carter et al., 2020). 


\section{Literature review}

This literature review will focus on perceived barriers that faculty professors face when using technology for distance teaching and creating videos.

The physical limitations brought by the first COVID19-lockdown in Spain from 13 March to 30 April 2020, created a situation which not only changed daily life for educators, but also brought about an opportunity to explore new pedagogical methods of teaching. Indeed, as there were no established protocols, professors could follow their own instincts in setting course requirements. Also, several challenges had to be addressed, such as data protection and the fact that not all platforms are adequate for remote teaching. It must be clarified that remote teaching in this case refers to working from home which cannot be assimilated with distance teaching or learning. Remote teaching involves the use of available tools for delivering educational materials that would be normally be delivered in face-to-face courses (Mohmmed et al., 2020).

It is necessary to emphasize that, from 13 March to 30 April 2020 we were living under emergency conditions which raised several questions. For instance, professors, as members of the community, are also professionals who have workers' rights. This means that they have a work schedule and requiring flexibility from teachers, as most universities did, should not mean additional work added to their workload while being flexible to accommodate students' needs.

\subsection{Professor's barriers with the use of technology in teaching}

Literature has discussed the barriers that are part of the use of information technologies in teaching. They include an absence of training, a lack of time, or organizational barriers. For instance, a qualitative study in the United States found different issues in the field of education. In this study, participants were a number of stakeholders including eight faculty members, four administrators, and five support staff. The study indicates that the main barriers to the use of digital technology in teaching include the amount of time needed to create activities, and to learn to use the technology. Other barriers include intellectual property concerns, content security concerns, and the availability of digital technologies (Polly et al., 2020).

In a study of engineering programs in Iran, it was found that the usefulness of Web 2.0 applications in teaching was not well understood. Nine faculty members participated and shared the difficulties that the limited access to these applications presented. In addition, they faced organizational barriers such as poor professional support or poor job promotion strategy (Zarei et al., 2017).

The use of technology in teaching also presents pedagogical barriers. For instance, in education programs in Israel, different barriers emerged in a qualitative study of 22 professors. Among them were the teaching style, a lack of technical knowledge, and a lack of experience in usage (Avidov-Ungar et al., 2018).

In the field of library and information science, other barriers were found in a study with participants from eight European universities. Among the obstacles were a lack of skills, a resistance to change and organizational barriers (Krtalić \& Mandl, 2019). 


\subsection{Professors' barriers in distance learning}

Distance learning professors perceive other barriers when adopting technology. In a United States study of 17 distance learning instructors, it was found that professors struggled with several issues, including a lack of compensation for time spent, inadequate training, increased workload, a lack of experience, and inconsistent administrative and technical support (Luongo, 2018).

There are also barriers relating to institutional support and technical issues. For instance, in a study of 117 professors in Saudi Arabia, the majority of whom were from the humanities and education fields, different barriers arose regarding the use of Blackboard Collaborate software. It was found that technical barriers caused the misuse of this tool. Other drawbacks were frequent internet disconnections and a bandwidth slow down when the number of users increased. In addition, there were institutional barriers, a lack of sufficient training, and a lack of technical support available on a permanent basis (Al Meajel \& Abdullah, 2018).

\subsection{Creating educational videos}

An educational video is audio-visual content that teaches students about a topic. When designing educational content for distance or remote learning, it is necessary to consider the creation of videos, especially when the education will be delivered by a hybrid model. Small lectures, training tutorials, and explanations may be incorporated into video-enhanced teaching. For instance, it was found that videos with QR-codes, together with paper-based material, were an effective way of teaching (Yahya et al., 2018).

Preparing educational videos is time-consuming and requires a significant degree of preparation for professors. They must have proper equipment with a professional microphone, a webcam, and software to edit the lecture (Boté-Vericad, 2021). During the coronavirus outbreak, access to a professional video editor was not always available. Most solutions involved improvising and creating live streaming videos with private university platforms or on social networking sites, which can be a suitable approach, although it is necessary to add a watermark to videos to identify the institution (Gómez et al., 2019).

Educational videos can be a useful part of the learning process, especially if students cannot attend a remote lecture. Students can play them back several times, and they can contain more than just educational content. For instance, in the education field in Australia, a quantitative study surveying 299 first-year bachelor-level students found that video feedback was preferred to written feedback to enhance the assessment process (West \& Turner, 2016).

\section{Methodology}

This paper focuses on analysing the perceived barriers of UB faculty on distance teaching and preparing educational content during the COVID-19 lockdown from 13 March to 30 April 2020. 
Due to the unique situation we faced at UB, it was possible to approach teaching staff with difficulties in adopting digital and distance teaching for this research. They had asked for help at the beginning of the lockdown. As a result, this research does not target teaching staff who are well-trained or highly motivated and already using digital elements. We were interested in finding out how a group of professors with little experience in distance teaching reacted to the new digital methods and whether they will continue to use digital modes of delivery in their teaching.

During the first two weeks of lockdown, from 13 March to 30 March 2020, the author of this paper created 30 video tutorials for the UB teaching community. These videos consisted mainly of practical instructions on how to create audio-visual content in order to deliver courses. They also explained how to use the internal resources provided by UB to publish audio-visual content, such as the Microsoft Stream platform, Blackboard Collaborate or using simple video editing software, along with editing tips. Moreover, professors had the ability to upload live-recorded sessions that were published internally in accordance with privacy regulations under the GDPR.

These 30 videos were uploaded to the Microsoft Stream platform, and they are still available for the whole university community to view. The community, in this case, are professors, students, and administrative staff.

In each video, the email address of the author of this paper was provided. Professors could add a comment to the video or send a direct email to the video creator with their questions. One of the issues of Microsoft Stream is that when a professor posted a comment on a video, it did not send an alert to respond immediately.

There were two solutions to this challenge. In every video, a comment was included to ask professors questions using an online group called Videos-STREAM in the Yammer community, which is another Microsoft product in UB's cloud. Subsequently, posted messages were received immediately. Viewers could also write a private email to the author.

During the first month of lockdown, we received more than 80 emails and more than 100 comments from videos. All the emails and comments related to procedures or how one software application was better than another. All related to urgent issues regarding the enhancement of digital skills. These emails showed that professors felt a need for technical support and there were no pedagogical questions.

Based on professors' emails and their concerns relating to educational content delivery, a self-administered qualitative survey was designed using Microsoft Forms. Two professors from the Library and Information Science department at UB, who are experts in qualitative methodologies, validated the survey, which included two types of questions: demographic questions and nine (9) topic-based open-ended questions. Qualitative survey data shows the participants' language and terminology by typing responses in their own words rather than selecting their responses from pre-determined response options (Braun et al., 2020).

The open-ended questions were as follows:

1. Could you explain if have you ever created videos for teaching? 
2. What technological barriers did you face when making videos with teaching materials?

3. Do you feel comfortable with this type of technology?

4. Right now, how do you view your experience creating videos with teaching materials?

5. If you have taken live classes, what has been your experience? By what means?

6. What has changed since you did face-to-face teaching?

7. Do you think you will be able to reuse the videos you created?

8. Once you have seen how videos can be created with teaching materials, do you think you will generate more teaching materials in video format once we return to face-to-face teaching?

9. Finally, in addition to producing videos, did you use other alternative tools (in addition to Skype Business or Blackboard-Collaborate) and how has your experience been?

The survey was sent to professors who communicated via comments on the videos, on the Yammer community, or email. Using a convenience sample method, a total of 41 emails were sent to different UB professors from different specialities. From these 41 emails, seven were addressed to the Library and Information Science Department. Professors had ten days to answer the survey, bearing in mind that they also had to tend to their daily academic life in the lockdown period as well as with their private lives. Then, professors could answer the survey at their own pace. Data was collected from 20 April to 30 April 2020.

Data was analysed using the six phases of reflexive thematic analysis method proposed by Braun and Clarke (2006). Thematic analysis is a flexible instrument that permits identifying themes and patterns in qualitative data (Berlanda et al., 2020). Using Atlas version 8 software, answers were coded and clustered into themes and subthemes. To end, we casually explore some of the commonalities and differences between professors from Engineering and Science and those from Humanities and Social Science.

\section{Results}

The answers from the first 29 (70,73\%) emails answered by professors to this qualitative survey led to a saturation point and information was redundant (Braun et al., 2019), so no further professors were contacted. Therefore, results and analysis are based on a sample of $N=29$. The research areas of these professors were varied as shown in Table 1.

In terms of age, professors' average age was $\bar{x}=52$ years. In terms of gender men $=13(44.82 \%)$, women $=16(55.17 \%)$.

\subsection{Data analysis and theme generation}

Following reflexive thematic analysis (Braun \& Clarke, 2006), we read the answers carefully and we grouped the relevant data obtained from the research questions into 
Table 1

Professors' research areas

\begin{tabular}{lclc}
\hline Field & $N$ & Field & $N$ \\
\hline Biochemistry & 1 & Library and Information Science & 3 \\
Biomedical Engineering & 1 & Marketing & 1 \\
Cellular Biology & 1 & Nursery & 2 \\
Economy & 3 & Pharmacy & 2 \\
Geography & 1 & Political Science & 1 \\
History & 1 & Psychology & 4 \\
Immunology & 1 & Philology & 2 \\
Law & 4 & Sociology & 1 \\
\hline
\end{tabular}

Table 2

Themes and subthemes created from reflexive thematic analysis

\begin{tabular}{ll}
\hline Themes & Subthemes \\
\hline Educational material delivery & Quality of educational videos \\
& Teaching with Social Networking Sites \\
& Technical issues \\
& Availability of university resources \\
& Future production of educational videos \\
Professors' issues in distance teaching & Teaching methodology \\
& Additional working hours. \\
& Professors' reactions \\
& Professors' satisfaction in creating videos or live sessions \\
& Professors' training \\
& Students' attitudes and implications on teaching metho- \\
dologies
\end{tabular}

initial codes. Names for the codes were generated through inductive reasoning. Based on their similarity, codes were combined into subthemes. In a final and recursive review and interpretation of the data, subthemes were grouped into two main overarching themes, a) educational material delivery and b) professors' issues on distance teaching. Themes and subthemes can be observed in Table 2.

\subsection{Theme 1: Educational material delivery}

Participants expressed their opinions about the delivery of the educational content and its relation to changes in their teaching methods. Professors were aware of the quality of the content they delivered but they had to overcome several technical issues. Moreover, some of them also used social networking sites (SNS), reasoning that it was easier to reach some students with connection limitations. The majority said their experiences were satisfactory, but they do not wish to keep their materials to be publicly available on a permanent basis. They would prefer to generate new material in order to have a higher level of quality.

\subsubsection{Subtheme 1: Quality of educational videos}

In their responses, professors had concerns about the quality of the videos they created. These concerns were meaningful in the sense that videos they created or live 
sessions they recorded were done only for this occasion. In their opinion, the videos need further editing before being publicly available.

"I'm thinking about it. The reality is that they have been useful in an emergency situation like the one we have experienced, but I am not clear that the quality is enough to make them public. I guess, for the next course, I will use them as additional material for the students." (Biomedical Engineering professor)

In addition, a few participants made the distinction between what can be found on YouTube in comparison to the content that they create. This meant that, because of the educational environment, their wish for content quality is greater.

"I don't find it sufficient to upload a video that looks like a tutorial found on Youtube on "how to fix the wheel of your bike in 5 minutes." (Spanish Philology)

Professors also felt that the content of educational videos should be different than that of a lecture. Videos need to be summarized with a focus on the main points of the lecture. This led to the question of whether professors agreed.

"I think it is necessary to be very synthetic, which helps in explaining key concepts and basic principles of the subject you teach." (History professor)

\subsubsection{Subtheme 2: Teaching with social networking sites}

Some professors have been teaching via social networking sites (hereafter SNS), for a variety of reasons, especially at the beginning of the lock-down. The main reason was because most students had better access to courses because of their connectivity problems. Many students found it easier to follow the teaching session from a mobile device with a SNS such as Twitter, Instagram or YouTube, rather than from a virtual campus on a computer. This presented some difficulties to both professors and students.

"I was confined earlier than the rest of the population and I tried "live" via Instagram. I have students with poor connectivity and sometimes it is easier for them to follow the class with Instagram." (Law professor)

Few professors delivered content to students with SNS like Twitter or YouTube and their reasons were varied. It was likely easier than with the UB cloud, especially when students had poor connectivity.

"Basically, I recorded lectures in PowerPoint and saved them to video which I uploaded to YouTube." (Pharmacy professor)

\subsubsection{Subtheme 3: Technical issues}

Instructors identified a wide variety of technical issues. The recurring issues were a lack of equipment, having old equipment at home, poor sound quality for live sessions or recorded videos, and especially, bandwidth problems that did not provide good conditions for teaching. Similarly, professors found that students also had the same issues. 
"Sometimes the internet connection fails." (Law professor).

In addition, most of them said that they had old equipment at home, making it difficult to create good quality material and to do live sessions.

"I have a laptop that is too old and when I create videos, the audio is of poor quality. In addition, it takes a long time to save a video.” (Immunology professor)

A lack of equipment at home was also reported by professors. In some cases, they had to buy their own equipment.

"I had to buy a tablet to write formulas in order to do the classes again." (Economics professor)

Moreover, those with better teaching conditions found that they had technology limitations not only with live sessions but also when they tried to create videos. These limitations affected their teaching sessions and they questioned whether students understood their lectures.

"BBCollaborate software does not permit an instructor to watch all students in class. Moreover, the students turn off the camera. Without seeing their faces, or seeing them only on video, it becomes very difficult to know their degree of attention or whether they understand what is being explained or practiced." (LIS professor)

\subsubsection{Subtheme 4: Availability of university resources}

As members of the university, professors had access to technical resources. In this subtheme there are two recurring topics. The first was the use of the available university tools and the second was the use of tools other than those provided by the university. Some professors said that they were unaware of the corporate tools available and that they used alternative tools.

For instance, corporate tools were used for sessions, such as Skype Business at the beginning of the lock-down and later, Blackboard Collaborate. In addition, professors had the ability to upload videos to the Microsoft Stream platform for internal use and to make them available to students. Alternative tools used for live sessions were Google Hangout, Google Meet, Jitsi, or Zoom. Nevertheless, overall they felt that Blackboard Collaborate was a good experience.

"I have used Zoom and Google Hangouts. However, I prefer BlackboardCollaborate for its simplicity and integration into the virtual campus." (Nursing professor)

\subsubsection{Subtheme 5: Future educational video production}

Professors were asked about the creation of educational videos, and they shared their thoughts about the creation process and the possibility of using them again later. In most cases, professors said that they will produce videos for some occasions as a supplementary material or for $\mathrm{PhD}$ students. 
"I will probably do it for $\mathrm{PhD}$ training activities, keeping in mind that many $\mathrm{PhD}$ students are in their respective countries." (Psychology professor)

\subsection{Theme 2: Professors and distance teaching}

This theme is about the methodology and its changes to the online environment, as well as changes in the transmission of knowledge and the sense that instructors were working additional hours. There was also discussion about the possible influence of students' behaviour in live sessions to their teaching methodology.

\subsubsection{Subtheme 1: Teaching methodology}

For the most part, professors felt that distance teaching changed their teaching methodologies. Most of them had to create new educational materials for their students. In addition, they found that distance teaching is completely different from face-to-face teaching, as their relationship with students is completely different and engagement in class is lost. In regard to class preparation, they felt that they needed much more time to prepare for classes and that course preparation needed to be more detailed.

"Interaction with students is what I miss the most." (LIS professor)

In some specialities where discussion is a key part of class time, they found that live discussions are more difficult and there was no ability to improvise in class.

"In law, connection is necessary because the debate among students, especially when talking about human rights, is critical. Plus, I usually do role-playing games with real cases. This is more difficult to do online." (Law professor)

\subsubsection{Subtheme 2: Additional working hours}

Most participants said that remote teaching means longer working hours. This increased workload was felt not only in their daily teaching, but also in the time required to prepare and produce videos. This meant a greater workload, with longer work days than before due to the time required to create videos or do live sessions.

"Live teaching sessions and the creation of videos requires a lot more time than before; I spent an average of 10 hours in front of the computer every day." (Psychology professor)

\subsubsection{Subtheme 3: Professors' reactions}

Professors reacted to this situation differently. Some of them could not create videos or do live sessions for one reason or another. For instance, some had old equipment, a poor Internet connection, or a greater number of students enrolled in their courses. Then, they needed to provide additional online educational materials when necessary. Others felt panic or stress when online. 
"I haven’t done live classes yet, assembling 140 students is tricky." (Immunology professor)

Video content curation was also an activity undertaken by some professors. They selected educational videos from the Internet to provide to students for a variety of reasons, most often because there was existing material so they did not need to create new material.

"There are already many videos available online. I do not need to create more videos. You have to take advantage of what already exists on the internet." (Psychology professor)

\subsubsection{Subtheme 4: Professors' satisfaction in creating videos or live sessions}

Overall, professors felt that their experience teaching online was positive. However, they are not satisfied with their results when recording live sessions or creating a set of videos. They needed to do so on an emergency basis and, since their reaction was fast, they seem to be happy with their experience.

"I have done sessions with Blackboard Collaborate and I have recorded them so that students, especially those unable to attend can retrieve them. The experience is good, especially the interaction and being able to answer questions." (LIS professor)

\subsubsection{Subtheme 5: Professors' training}

This new situation led many professors to discover that they did not have adequate training. Thus, they have managed the situation as best they could although their experience with live teaching sessions and video creation were limited.

Regarding their lack of training, professors said they had not previously needed to create videos for their courses. However, the learning curve for them, in many cases, has been steep:

"In my case, not knowing how to manage some tools was an issue to daily teaching. I personally think that we need more training." (LIS professor)

Others also admitted to challenges with not having adequate skills and a steep learning curve for creating videos as well as doing live sessions with unfamiliar software.

"My main barriers have been the learning curve, the speed with which we have had to adapt and the lack of training and material." (Pharmacy professor)

\subsubsection{Subtheme 6: Students' attitudes and implications on teaching methodologies}

Professors observed a few new situations regarding students' attitudes. Two common situations they report are that, for one, students are hidden behind the camera and the majority have their cameras turned off. Professors doubt whether students really understood their explanations and found that students participated less in their courses: 
Table 3

Professor's $(N=29)$ facing barriers on distance teaching: data comparison between Engineering and Science $(n=11)$ and Humanities and Social Sciences $(n=18)$

\begin{tabular}{|c|c|c|c|c|}
\hline \multirow[t]{2}{*}{$\begin{array}{l}\text { Themes and } \\
\text { subthemes }\end{array}$} & \multicolumn{2}{|c|}{$\begin{array}{l}\text { Engineering and Science } \\
\qquad n=11\end{array}$} & \multicolumn{2}{|c|}{$\begin{array}{l}\text { Humanities and Social Sciences } \\
\qquad n=18 \\
\end{array}$} \\
\hline & Quotations & $\%$ & Quotations & $\%$ \\
\hline Educational material delivery & 75 & $40.32 \%$ & 79 & $33.33 \%$ \\
\hline Quality of educational videos & 1 & $1.33 \%$ & 2 & $2.53 \%$ \\
\hline Teaching with SNS & 1 & $1.33 \%$ & 1 & $1.27 \%$ \\
\hline Technical issues & 19 & $25.33 \%$ & 19 & $24.05 \%$ \\
\hline Availability of university resources & 44 & $58.67 \%$ & 38 & $48.10 \%$ \\
\hline $\begin{array}{l}\text { Future production of educational } \\
\text { videos }\end{array}$ & 10 & $13.33 \%$ & 19 & $24.05 \%$ \\
\hline Professors and distance teaching & 111 & $59.67 \%$ & 158 & $66.67 \%$ \\
\hline Teaching methodology & 21 & $18.92 \%$ & 51 & $32.28 \%$ \\
\hline Additional working hours & 6 & $5.40 \%$ & 4 & $3.18 \%$ \\
\hline Professors' reactions & 10 & $9.01 \%$ & 10 & $7.94 \%$ \\
\hline $\begin{array}{l}\text { Professors' satisfaction in creating } \\
\text { videos or live sessions }\end{array}$ & 42 & $37.84 \%$ & 44 & $34.92 \%$ \\
\hline Professors' training & 25 & $22.52 \%$ & 32 & $20.25 \%$ \\
\hline $\begin{array}{l}\text { Students' attitudes and implications } \\
\text { on teaching methodologies }\end{array}$ & 7 & $6.31 \%$ & 17 & $10.76 \%$ \\
\hline
\end{tabular}

"There is less interaction. Many students turn off the camera and this gives me a strange feeling." (Political Science professor)

Another recurring situation arises due to technology limitations when students have their cameras turned off. To professors, it was very difficult, in the absence of non-verbal cues, to know if students' attention levels or even their comprehension level was enough.

"What bothers me the most is not seeing the students' faces ... to me, non-verbal communication with them is very important." (LIS professor)

\subsection{Descriptive differences among groups of professors}

Professors $(n=29)$ were grouped according to whether they are part of the fields of Engineering and Science $(n=11)$ or Humanities and Social Sciences fields ( $n=$ 18) to determine if there were differences between them in terms of the themes and sub-themes that emerged in the qualitative survey (Table 3).

In the first theme (educational material delivery), professors from both fields found similar technical issues. In the second theme (professors and distance teaching) in regard to teaching methodology, it indicates that professors in the Humanities and Social Sciences, perceived more changes in their methodology for distance teaching than those in Engineering and Science. Regarding students' attitudes there is a slight difference on the perceptions of professors in the Humanities and Social Science than professors of Engineering and Science. Through such general observations, the results may offer some social implications in that stereotypes among professors of these two 
different areas do not exist. For example, they share similar issues, such as dealing with technology or their challenges with their training. Although, there would need to be more research conducted in this area, for a more granular analysis.

\section{Discussion and conclusions}

This paper explores the perceptions and challenges that a group of professors at the University of Barcelona (UB) had to deal with when undertaking emergency remote teaching during the first COVID-19 lockdown in Spain from 13 March to 30 April 2020. These professors taught their courses by creating educational videos or presenting live lectures to their students. Across the qualitative survey, consistent themes and subthemes emerged from the thematic analysis, centred on educational content delivery and professors' perceptions.

In regard to the first research question, the analysis leads with the theme of educational content delivery and its subthemes. In the analysis, it is possible to observe that the major barriers professors faced were technical issues such as a lack of connectivity or inadequate equipment.

The varying access to a reliable broadband connection could lead students and professors to a digital divide. This inequality meant that some professors published videos through social networking sites like Instagram or YouTube. This enabled students to watch the session several times, similar to a previous case study in the field of mechanical engineering in Oman (Mohmmed et al., 2020). In addition, students used their mobile devices for learning, especially if they were living outside big urban centres. In a study in Spain, it was found that one in three students did not have adequate technological resources at home during the lockdown (Rodicio-García et al., 2020).

Many professors had technical problems when creating educational videos, although most managed to create videos to facilitate student learning. In other studies, video creation helped students improve cross-curricular competencies (Orús et al., 2016). In some cases, creating videos had a positive impact on academic development and improved student learning (Ruiz-Tovar et al., 2019; Moreno-Guerrero et al., 2020; Hervas et al., 2020).

Professors had concerns about the quality of the material they created and delivered. For example, they could not re-edit videos to improve their quality because they did not have video editing software. At the same time, lecturers mostly agreed to create new content for future use as it would allow them to generate better material. In the case of videos, it was found that creating multilingual video subtitles increases visibility (Valor et al., 2018) and facilitates cultural competences and student knowledge (Lin \& Wang, 2018). This can be a motivation for professors to not only improve their engagement with students, but also to increase the quality of their educational materials 
The use of alternative tools for live teaching besides those provided by the University of Barcelona, such as Zoom or Google Meetings, was not typical among this group of professors. Finally, most preferred to use Blackboard Collaborate to deliver live sessions even with its technological limitations. As a result, it seems that more training was necessary to them. In addition, the use of third-party software cause lack of face-to-face contact, the effect to talk to an empty class or talking to turned-off cameras. Previous studies reported similar findings in Australia (Chen et al., 2019). In addition, in the field of psychology in Spain it was found that professors required more training not in the use of the platform itself, but also in pedagogical aspects (Villalón et al., 2019).

In relation to the second research question concerning the changes that were made by professors regarding their teaching methodology, the analysis leads with the theme of professors and distance teaching and its subthemes. In this theme there are issues that influenced professors and their teaching methodology.

In the analysis, it is possible to observe that the major barriers professors faced were technical issues such as a lack of connectivity or inadequate equipment.

One of the recurring answers is that professors had to change their methodology even if it exposed their own limitations or deficiencies. This is a change not only in how they deliver materials but also in how they organise students, particularly with groups that were too big. In a similar study in the United States, it was found that professors did not have sufficient time to prepare instruction for the online format because of the short transition time to remote teaching (Njoki, 2020).

Professors also said that creating educational videos and attending class sessions led to longer working hours. However, the majority were satisfied with the videos they created in this first experience. Moreover, those who created videos felt that they needed more training as well as the necessary equipment. This demonstrates an absence of material and also a lack of digital literacy on the part of the professors themselves. This situation was also reported in similar studies (Luongo, 2018; AvidovUngar et al., 2018).

Besides missing technical and digital skills, professors also lacked skills in adopting digital teaching methods, particularly because of their context. As they led face-toface courses, digital literacy was not an essential skill for them. In sum, it seems obvious that remote teaching requires some preparation as well as careful design. In particular, the interactions between professors and students must be kept in mind when designing digital tools (Smith, 2020).

Finally, what also influenced professors when teaching was how the majority of students were hidden behind their turned-off cameras. This causes a lack of focus while teaching online sessions due to the absence of eye contact, which in is necessary in some specialities such as Library and Information Science, Law or Psychology. A previous study reported similar findings (Mohmed et al., 2020).

This study has some limitations. Since participating professors were the target of the videos, it is possible that there were professors who watched the videos but did not provide any comments or email the author. Another limitation is that participants 
from other universities are not included since videos were addressed to professors at the University of Barcelona. A further limitation is that the sample is small and, therefore the results should not be generalised. However, the whole group represented professors without prior video creation experience. Future research could include professors from other universities.

Finally, some conclusions can be drawn from this study. While professors seem satisfied with their results of video creation and live sessions during the first COVID19 lockdown in Spain, the findings also indicate the need for continuous training in two areas. First, in improving their digital literacy not only to create videos in the next terms, but also for distance teaching. Second, while they used the resources provided by the university, technical issues must be solved. To end, the acquisition of new methodologies suited to this new environment, and ongoing training in the use of such methodologies will assist professors to deliver distance teaching in a hybrid model going forward.

\section{References}

Affouneh, S., Salha, S., \& Khlaif, Z. (2020). Designing quality e-learning environments for emergency remote teaching in coronavirus crisis. Interdisciplinary Journal of Virtual Learning in Medical Sciences, 11(2), 135-137.

Al Meajel, T.M., \& Sharadgah, T.A. (2018). Barriers to Using the Blackboard System in Teaching and Learning: Faculty Perceptions. Tech Know Learn, 23, 351-366. doi: 10.1007/s10758-017-9323-2.

Alegre, A., Bernal, D., \& Mumbrú, A. (2016). Enquesta de condicions de vida i participació dels estudiants universitaris. ECoVIPEU-UB. Retrieved from http://hdl.handle.net/2445/104204.

Alexander, B. (2020). Talking about COVID-19 and higher education with the Wall Street Journal. Retrieved from https://bryanalexander.org/interviews/talking-about-COVID-19-and-higher-educationwith-the-wall-street-journal/.

Anderson, J. (2020). Sweden is taking a very different approach to COVID-19. Retrieved from https://qz. com/1842183/sweden-is-taking-a-very-different-approach-to-covid-19/.

Avidov-Ungar, O., Leshem, B., Margaliot, A., \& Grobgeld, E. (2018). Faculty use of the active learning classroom: barriers and facilitators. Journal of Information Technology Education Research, 18, 485-504. doi: 10.28945/4142.

Berlanda, S., de Cordova, F., Fraizzoli, M., \& Pedrazza, M. (2020). Risk and protective factors of wellbeing among healthcare staff. A thematic analysis. J Environ Res Public Health, 17, 6651. doi: 10.3390/ijerph17186651.

Bonaccorsi, G., Pierri, F., Matteo, C., Flori, A., Galeazzi, A., Porcelli, F., Schmidt, A. L. et al. (2020). Economic and social consequences of human mobility restrictions under COVID-19. In: Proceedings of the National Academy of Sciences July 2020, 117(27), 15530-15535. doi: 10.1073/pnas.2007658117.

Borzkurt, A., \& Sharma, R. (2020). Emergency remote teaching in a time of global crisis due to Corona Virus pandemic. Asian Journal of Distance Education, 15(1), i-iv.

Boté-Vericad, J.-J. (2021). Unterrichten in den Bibliotheks- und Informationswissenschaften: Videoherstellung zur Bereitstellung von Bildungsinhalten. Mitteilungen Der Vereinigung Österreichischer Bibliothekarinnen Und Bibliothekare, 73(3-4). doi: 10.31263/voebm.v73i3-4.5380.

Braun, V., \& Clarke, V. (2006). Using thematic analysis in psychology. Qualitative Research in Psychology, 3(2), 77-101. doi: 10.1191/1478088706qp063oa.

Braun, V., Clarke, V., Boulton, E., Davey, L., \& McEvoy, C. (2020). The online survey as a qualitative research tool. International Journal of Social Research Methodology. doi: 10.1080/13645579. 2020.1805550 
Braun, V., Clarke, V., Hayfield, N., \& Terry, G. (2019). Thematic Analysis. In: Liamputtong, P. (eds) Handbook of Research Methods in Health Social Sciences. Springer, Singapore. doi: 10.1007/978981-10-5251-4_103.

Calduch, I., Álamo, E., Francàs, J., Guitérrez, N., Valenzuela, M., \& Daza, L. (2017). Perfil de los estudiantes recién llegados a la Universidad de Barcelona. Retrieved from http://hdl.handle.net/2445/ 116229.

Carter, R., Rice, M., Yang, S., \& Jackson, A. (2020). Self-regulated learning in online learning environments: strategies for remote learning. Information and Learning Sciences, 121(5/6), 321-329. doi: 10.1108/ILS-04-2020-0114.

Chen, J., Dobinson, T., \& Kent, S. (2019). Lecturers' perceptions and experiences of Blackboard Collaborate as a distance learning and teaching tool via Open Universities Australia (OUA). Open Learning: The Journal of Open, Distance and e-Learning, 35(3), 222-235. doi: 10.1080/02680513.2019.1688654.

Dahlberg, M., Edin, P., Grönqvist, E., Lyhagen, J., Östh, J., Siretskiy, A. et al. (2020). Effects of the COVID-19 Pandemic on Population Mobility under Mild Policies: Causal Evidence from Sweden. Retrieved from http://arxiv.org/abs/2004.09087.

Durksen, T., \& Klassen, R. (2018). The development of a situational judgement test of personal attributes for quality teaching in rural and remote Australia. The Australian Educational Researcher, 45, 255-276.

Espinoza, B., Castillo-Chavez, C., \& Perrings, C. (2020). Mobility restrictions for the control of epidemics: When do they work? PLoS ONE, 15(7), e0235731.

Fang, H., Wang, L., \& Yang, Y. (2020). Human Mobility Restrictions and the Spread of the Novel Coronavirus (2019-nCoV) in China. Working paper No. 26906, National Bureau of Economic Research, March 2020. doi: 10.3386/w26906.

Flynn, A., \& Kerr, J. (2020). Remote teaching: a practical guide with tools, tips, and techniques. Retrieved from https://openlibrary-repo.ecampusontario.ca/jspui/handle/123456789/654.

Gacs, A., Goertler, S., \& Spasova, S. (2020). Planned online language education versus crisis-prompted online language teaching: Lessons for the future. Foreign Language Annals. 53(2), 380-392.

Gobierno de España. (2020). Real Decreto 463/2020, de 14 de marzo, por el que se declara el estado de alarma para la gestión de la situación de crisis sanitaria ocasionada por el COVID-19. Retrieved from https://www.boe.es/eli/es/rd/2020/03/14/463/con.

Gómez, J., Rodríguez-Socarras, M., Cacciamani, G., Meneses, A., Okhnuvo, Z., Gurp, M. et al. (2019). Live videos shared on social media during urological conferences are increasing: Time to reflect on advantages and potential harms. An ESUT-YAU study. Actas Urológicas Españolas (English Edition), 43(10), 551-556. doi: 10.1016/j.acuroe.2019.05.011.

Hervas, J., Medina, J., \& Paz, M. (2020). Participants' views of the use of video in lesson study in higher education in Spain: An exploratory multiple case study. Journal Research on Technology in Education. doi: 10.1080/15391523.2020.1734509.

Hodges, C., Moore, S., Lockee, B., Trust, T., \& Bond, A. (2020a). The difference between emergency remote teaching and online learning. Retrieved from https://er.educause.edu/articles/2020/3/the-differencebetween-emergency-remote-teaching-and-online-learning.

Hodges, C. B., Moore, S. L., Lockee, B. B., \& Bond, M. A. (2020b). Instructional design for emergency remote teaching (ERT) - Job Aid. Leadership, Technology, and Human Development Faculty Publications, 119. doi: 10.20429/10.1007_978-981-15-7869-4_3_1.

Krtalić, M., \& Mandl, T. (2019). Didactic Trends in LIS Education and their Reflection in Curricula Design. Education for Information, 35(2), 65-86. doi: 10.3233/EFI-190268.

Lin, Y., \& Wang, H. (2018). Using enhanced OER videos to facilitate English L2 learners' multicultural competence. Computers and Education, 125, 74-85.

Luongo, N. (2018). An examination of distance learning faculty satisfaction levels and self-perceived barriers. Journals of Educator Online, 15(2). doi: 10.9743/jeo.2018.15.2.8.

Mbabazi, B., Ali, G., Geoffrey, A., \& Lawrence, N. (2018). Mobile Devices for Learning in Universities: Challenges and Effects of Usage. Retrieved from https://pdfs.semanticscholar.org/e8db/4c4979 b609acc46628be3a07f4d363a563bc.pdf.

Mejía, R. (2020). M-Learning: características, ventajas y desventajas, uso. Revista Tecnológica-Educativa Docentes 2.0, 8(1), 50-52. 
Mohmmed, A. O., Khidhir, B. A., Nazeer, A., \& Vijayam, V. J. (2020). Emergency remote teaching during Coronavirus pandemic: the current trend and future directive at Middle East College Oman. Innovative Infrastructure Solutions, 5(72). doi: 10.1007/s41062-020-00326-7.

Moreno-Guerrero, A., Rodríguez-Jímenez, C., Gómez-García, G., \& Ramos, M. (2020). Educational innovation in higher education: Use of role playing and educational video in future teachers' training. Sustainability, 12(6). doi: 10.3390/su12062558.

Njoki, P. (2020). Remote Teaching of General Chemistry for Nonscience Majors during COVID-19. Journal of Chemical Education, 97(9), 2158-3162. doi: 10.1021/acs.jchemed.0c00864.

Nuño, A. (2020). Qué pasa con las universidades? Así están preparando la vuelta en plena pandemia. https://www.elconfidencial.com/alma-corazon-vida/educacion/2020-09-06/universidadescoronavirus-pandemia-medidas_2731640/.

Oranburg, S. (2020). Distance Education in the Time of Coronavirus: Quick and Easy Strategies for Professors. Duquesne University School of Law Research, paper No. 2020-02. doi: 10.2139/ssrn.3553911.

Orús, C., Barlés, M., Belanche, D., Casaló, L., Fraj, E., \& Guerrea, R. (2016). The effects of learnergenerated videos for YouTube on learning outcomes and satisfaction. Computers and Education, 95 , 254-269. doi: 10.1016/j.compedu.2016.01.007.

Polly, D., Martin, F., \& Guilbaud, T.C. (2020). Examining barriers and desired supports to increase faculty members' use of digital technologies: perspectives of faculty, staff and administrators. Journal of Computing in Higher Education. doi: 10.1007/s12528-020-09259-7.

Ramud, N., Muchtar, Z., \& Hutabarat, W. (2018). The development of flash program based mobile learning (m-learning) on colloidal system material. In: Striełkowski, W., \& Cheng, J. (Eds.). Proceedings of the 3 rd Annual International Seminar on Transformative Education and Educational Leadership, Medan City, Indonesia, 156-159.

Rodicio-García, M., Ríos-de-Deus, M., Mosquera-González, M., \& Penado Abilleira, M. (2020). La Brecha Digital en Estudiantes Españoles ante la Crisis de la COVID-19. Revista Internacional De Educación Para La Justicia Social, 9(3), 103-125. doi: 10.15366/riejs2020.9.3.006.

Roth, J., Chang, A., Ricci, B., Hall, M., \& Mehta, N. (2020). Why Not a Podcast? Assessing Narrative Audio and Written Curricula in Obstetrical Neurology. Journal of Graduate Medical Education, 12(1), pp. 86-91. doi: 10.4300/JGME-D-19-00505.1.

Ruiz-Tovar, J., Prieto-Nieto, I., García-Olmo, D., Clascá, F., Enríquez, P., Villalong, R., et al. (2019). Training courses in laparoscopic bariatric surgery on cadaver thiel: results of a satisfaction survey on students and professors. Obesity Surgery, 29, 3465-3471. doi: 10.1007/s11695-019-04003-2.

Schlesselman, L. (2020). Perspective from a Teaching and Learning Center during Emergency Remote Teaching. American Journal of Pharmaceutical Education, 4(6). doi: 10.5688/ajpe8142.

Smith, E. (2020). 3 key things to consider when designing remote teaching. Retrieved from https://mru. arcabc.ca/islandora/object/mru\%3A461/.

Suyatna, A. (2019). Mobile phone utilization for learning: physics teachers' perception. Jurnal Ilmiah Pendidikan Fisika Al-BiRuNi. 8(2), 241-248.

Talidong, K. (2020). Implementation of emergency remote teaching (ERT) among Philippine teachers in Xi'an, China. Asian Journal of Distance Education, 15(1), 196-201.

Universitat de Barcelona. (2020). Convocatòria extraordinària del programa d'ajuts CONNECTA UB per garantir la connectivitat a Internet $i$ l'ús temporal d'ordinadors portàtils als estudiants de la Universitat de Barcelona amb dificultats econòmiques. Retrieved from https://seu.ub.edu/ajutsPublic/ showPublicacion/134721.

Valor, J., Baquero-Arnal, P., Civera, J., Turró, C., \& Juan, A. (2018). Multilingual Videos for MOOCs and OER. Journal of Educational Technology \& Society, 21(2), 1-12.

Villalón, R., Luna, M., \& García-Barrera, A. (2019). Valoración y uso de la plataforma Blackboard Collaborate en una universidad a distancia: estudio de caso sobre las prácticas declaradas de docentes del Grado de Psicología. Digital Education, 35, 289-298. doi: 10.1344/der.2019.35.267-288.

West, J., \& Turner, W. (2016). Enhancing the assessment experience: improving student perceptions, engagement and understanding using online video feedback. Innovations in Education and Teaching International, 53(4), 400-410.

Whittle, C., Tiwari, S., Yan, S., \& Williams, J. (2020). Emergency remote teaching environment: a 
conceptual framework for responsive online teaching in crises. Information and Learning Sciences, $121(5 / 6), 311-319$

Wolpaw, J., \& Harvey, J. (2020). How to podcast: A great learning tool made simple. The Clinical Teacher, $17(2), 131-135$.

Yahya, F., Abas, H., \& Yussof, R. (2018). Integration of screencast video through QR code: an effective learning material form m-learning. Journal of Engineering Science and Technology. 1-13. doi: 10.3991/ijim.v13i10.11305.

Zarei, A., Mohd-Yosuf, K., Daud, M., \& Azizi, N. (2017). Web 2.0 applications for engineering education: Faculty members' perception, barriers, and solutions. Computer Application in Engineering Education, 25(3). doi: $10.1002 /$ cae. 21812 . 